American Journal of Pharmaceutical Education 2020; 84 (10) Article 7945.

\title{
RESEARCH
}

\section{An Investigation of Prevalence and Predictors of Disengagement and Exhaustion in Pharmacy Students}

\author{
Madeline Fuller, ${ }^{\mathrm{a}}$ Aric Schadler, MS, ${ }^{\mathrm{a}, \mathrm{b}}$ Jeff Cain, EdD, $\mathrm{MS}^{\mathrm{a}}$ \\ ${ }^{a}$ University of Kentucky College of Pharmacy, Lexington, Kentucky \\ b Kentucky Children's Hospital, Lexington, Kentucky \\ Submitted November 27, 2019; accepted April 17, 2020; published October 2020.
}

\begin{abstract}
Objective. To determine the prevalence of burnout in first, second, and third professional year (P1, P2, and P3) pharmacy students at a single institution and identify predictors of higher burnout scores.

Methods. A 31-question anonymous online survey was developed and administered to a total of 390 P1, P2, and P3 students at the University of Kentucky College of Pharmacy. The survey consisted of a modified version of the 16-question Oldenburg Burnout Inventory (OLBI) and 14 additional questions related to demographic and co-curricular and extracurricular related questions. Descriptive and inferential statistical analyses were conducted as appropriate to determine differences among the variables studied and to identify predictive variables of disengagement and emotional exhaustion.

Results. Seventy-five percent of invited students participated in the study. Results of the analyses showed that P1 students had significantly lower engagement scores than both P2 and P3 students, and that P2 students were significantly less exhausted than P1 and P3 students. There was a lack of correlation between burnout scores and students' postgraduate goals, curricular involvement, and work responsibilities. Married students reported being significantly less exhausted than unmarried students. Conclusion. This study added to the growing evidence that pharmacy students have relatively high rates of disengagement and emotional exhaustion. Because the variables expected to contribute to burnout were not found to be predictive in this study, further analyses examining the positive and negative predictive factors associated with burnout scores in pharmacy students are needed. Identifying these factors would allow targeted interventions to be made early in the academic careers of students most susceptible to burnout.
\end{abstract}

Keywords: burnout, well-being, stress

\section{INTRODUCTION}

The recognition of burnout in the profession of pharmacy has been increasing over the last five years. Several national organizations, including the American Association of Colleges of Pharmacy, the American Society of Health-Systems Pharmacists, and the National Academy of Medicine, have been devoting resources to help educators and health care professionals combat the negative effects that burnout has on practitioners, residents, students, and ultimately patients. ${ }^{1-3}$

Burnout is defined by the Merriam-Webster.com Dictionary as "exhaustion of physical or emotional strength or motivation usually as a result of prolonged stress or frustration." "The World Health Organization

Corresponding Author: Jeff Cain, University of Kentucky, College of Pharmacy, 114M Lee T. Todd, Jr. Bldg., 789 S. Limestone Dr., Lexington, KY 40536-0596. Phone: 859-2574429. Email: jeff.cain@uky.edu
(WHO) issued a statement in May 2019 stating that burnout is an "occupational phenomenon" recognized in the International Classification of Diseases, 11th revision (ICD-11). The WHO definition of burnout focuses on displeasure with one's job, fatigue, and reduced efficiency in the workplace. ${ }^{5}$ Two key components that are well defined that contribute to burnout are emotional exhaustion and disengagement. Emotional exhaustion is best described as a state of mental fatigue perpetuated by factors such as constant stress and emotionally demanding work. ${ }^{6}$ Disengagement as defined by Reis and colleagues is a lack of connection to an obligation, or a "loss of concern of the contents. . of one's work.",

The prevalence of burnout among physicians, medical students, and other health care providers has been well reported. Rothenberger's systematic review revealed that burnout among medical practitioners is greater than $50 \%$, and that US medical students, physicians in training, and practicing physicians are at significant risk. ${ }^{8}$ 


\section{American Journal of Pharmaceutical Education 2020; 84 (10) Article 7945.}

Similarly, a meta-analysis by Frajerman and colleagues of 24 studies on medical student burnout found that $44 \%$ of medical students experienced burnout prior to starting residency. ${ }^{9}$ Data regarding burnout rates in pharmacy students prior to graduation, however, is sparse. Silva and Figueiredo-Braga compared rates of burnout in pharmacy students in their first two and last two years of their program and the correlation of these rates to students' satisfaction with their pharmacy education. Emotional exhaustion and depersonalization, along with the empathy levels of the participating students, were also assessed. Depersonalization is the dissociation of emotions from personal interactions, especially as it applies to the provision of health care to patients. ${ }^{6,10}$ Study results showed that third and fourth professional year (P3 and P4) students had higher depersonalization scores than students in earlier years of the program. First and second professional year (P1 and P2) students also having significantly more satisfaction with academics. It was found that for $39 \%$ of students, burnout was the cause of their dissatisfaction. ${ }^{11}$ Through an online survey, Kaur and colleagues assessed the rates of burnout and engagement in P1 and P2 pharmacy students and the relation of burnout to the students' self-perceived academic ability. Results showed that higher rates of burnout negatively impacted students' view of their apparent academic success, with student dedication having a beneficial impact on self-perception. ${ }^{12}$

One question that has not been answered is whether the pressure on students with higher workloads and extracurricular activities contributes to burnout. In an increasingly competitive postgraduate environment, many pharmacy students are finding ways to increase involvement, work experience, and cocurricular and extracurricular activities in order to differentiate themselves from other students. Initial studies of pharmacy student burnout have begun; however, positive and negative predictive factors and the correlation between burnout rates and postgraduate goals have not been explored. The purpose of this study was to determine the prevalence of burnout in P1, P2, and P3 pharmacy students and identify potential predictors of higher burnout scores.

\section{METHODS}

A 31-question anonymous online survey was developed at the University of Kentucky College of Pharmacy (UKCOP) in 2019. The survey consisted of the 16-question Oldenburg Burnout Inventory (OLBI), ${ }^{13}$ as well as 14 demographic and cocurricular and extracurricularrelated questions. Cocurricular activities (eg, pharmacy organization involvement) were considered part of the education process, as opposed to extracurricular activities (eg, community sports team membership), which were outside the scope of school purview. We revised all 16 of the OLBI survey questions slightly to more accurately target a student population. For example, we revised the phrase "There are days I feel tired before I arrive to work" to read "there are days I feel tired before I arrive to school."

The OLBI was developed to conceptualize and measure two concepts related to burnout: disengagement and exhaustion. ${ }^{13}$ While the Maslach Burnout Inventory is a widely used tool to assess burnout, the OLBI is considered to be worded more broadly and therefore applicable to multiple settings rather than just the workplace. ${ }^{14}$ The OLBI consists of eight questions that assess disengagement and eight questions that assess exhaustion. Each question is answered using a Likert scale with ratings from $1=$ strongly agree to $4=$ strongly disagree. A total individual burnout score was calculated based on each participants' answers. Questions 2, 3, 4, 6, 8, 9, 11, and 12 were reverse scored (eg, a score of 1 was changed to 4), because lower ratings on these items actually signify higher levels of burnout. Scores on the OLBI range from 16 to 64, with higher scores indicating higher rates of burnout.

The initial survey was pilot tested by three P3 students, one $\mathrm{P} 4$ student, and one pharmacy resident to assess the face validity of the instrument prior to distribution to the target population. Each participant in the pilot test assessed the survey for flow and ease of comprehension. Based on the feedback they provided, one OLBI question and one demographic question were slightly revised prior to conducting the survey.

The finalized survey instrument was administered to 390 UKCOP students in April 2019. The study population included $\mathrm{P} 1, \mathrm{P} 2$, and $\mathrm{P} 3$ pharmacy students enrolled in the didactic portion of the curriculum. A link to the survey instrument on Qualtrics (Qualtrics, LLC, Provo, UT) was distributed via email listserv and Canvas Learning Management System (Instructure Inc, Salt Lake City, UT). Participants were given a three-week window to complete the anonymous survey. The link to the survey was sent out approximately three weeks prior to final examinations and all surveys were completed prior to the start of final examinations. Participation was voluntary, with no incentives given for completing the survey. The study was approved as exempt by the University of Kentucky Institutional Review Board.

Statistical analyses were conducted using SPSS Statistics, version 23 (IBM Corporation, Armonk, NY) and SAS, version 9.4 (SAS Institute, Cary, NY) software. Two aggregate variables were calculated on subsets of the survey that measured disengagement and emotional exhaustion within the student population. Bivariate analyses on these two outcome variables were conducted to 


\section{American Journal of Pharmaceutical Education 2020; 84 (10) Article 7945.}

identify any significant differences between demographic and other categorical covariates of interest. Independent samples $t$ tests and ANOVA using a Bonferroni correction for post hoc pairwise comparisons were conducted as appropriate.

Multivariate logistic regression models were constructed to understand significant characteristics of students falling into the highest risk of disengagement and emotional exhaustion. High risk of disengagement and emotional exhaustion were defined as having scores in the top quartile of the two subscales respectively. The main effects included in each of the initial models were identified by the bivariate analysis and included years in school prior to pharmacy school, marital status, participation in extracurricular activities, working more than 10 hours per week, and year of pharmacy school. Additionally, two-way interactions between the covariates were also included in the models. Significance was determined as $p$ values less than .05 .

\section{RESULTS}

Of the 390 students invited to participate, 291 students completed the survey and all but one gave permission for their answers to be used for research purposes, resulting in an overall response rate of $75 \%$. Participant demographics including age, ethnicity, year in school, undergraduate course work, postgraduate career plans, and an assessment of extracurricular involvement are shown in Table 1. The gender of the participants was not collected; however, each class is made up of approximately $70 \%$ female students and $30 \%$ male students. The overall mean burnout score (maximum $=64$ ) for all participants was 45.3, with mean sums for exhaustion and disengagement being 23.3 and 22.0 respectively. The average score on the four-point scale was 2.7 for disengagement and 2.9 for exhaustion. Participant responses to each question assessing burnout are presented in Table 2 .

The modified (reverse scored) OLBI survey question on which students scored the lowest, with $78.7 \%$ answering strongly agree or agree, was question 1: "I always find new and interesting aspects in my school work." This question correlates with disengagement; thus, the majority of students' ratings indicated that they found their course work engaging. The question which students scored the highest was question number 2, "There are days I feel tired before arriving to school," with only $0.6 \%$ (two participants) choosing disagree or strongly disagree for this statement, which assessed exhaustion.

The results of the bivariate analysis for the disengagement variable showed a significant difference between students based on the number of years of pharmacy school they had completed $(p<.001)$. The post hoc analysis showed that P1 students had significantly lower engagement scores than both P2 and P3 students. The bivariate analysis for the exhaustion subscale again showed significant differences between students based on year in school $(p<.001)$, but the post hoc analysis showed that P2 students were significantly less exhausted than P1 or P3 students. Married students were also found to be significantly less exhausted than unmarried students $(p<.05)$. Other variables including postgraduate plans, work involvement, cocurricular and extracurricular involvement were not significant $(p>.05)$

Significant and marginal results in the bivariate analysis were considered for inclusion in the multivariate logistic modeling of students at high risk for exhaustion and disengagement. The model for disengagement resulted in only "year in pharmacy school" as a significant $(p<.001)$ predictor in the presence of the other variables. The P2 students were at three times higher risk for disengagement than P1 students (95\% CI, 1.6-6.0) and P3 students were at three times higher risk for disengagement than P1 students (95\% CI, 1.6-5.5). The model for exhaustion showed that year in pharmacy school $(p<.05)$ and marital status $(p<.05)$ were significant in the presence of the other variables. The P2 students were at 2.7 times higher risk for exhaustion compared to P1 students (95\% CI, 1.2-6.2) and P3 students were 23\% less likely to be at risk for exhaustion compared to P1 students (95\% CI, 0.4-1.5). Additionally, unmarried students were at 2.2 times higher risk for exhaustion compared to married students (95\% CI, 1.0-4.8). Two-way interactions were considered in both models but were not found to be significant in either. Results of $t$ tests of variables considered for inclusion in the multivariate logistic model are presented in Table 3.

\section{DISCUSSION}

There is a growing emphasis on student, resident, and practitioner well-being across multiple national pharmacy societies. While initial evidence indicates that burnout is prevalent in the workplace and the classroom, the reasoning behind what drives disengagement and exhaustion in students has not been researched. The purpose of this study was to assess factors potentially contributing to and associated with increased burnout scores of pharmacy students. This is believed to be the first study to explore various factors that influence the rates of burnout in pharmacy students at different points in the Doctor of Pharmacy curriculum.

While there have been few reports of burnout scores among students, the pharmacy student participants in this 


\section{American Journal of Pharmaceutical Education 2020; 84 (10) Article 7945.}

Table 1. Baseline and Descriptive Characteristics of Participants in a Study to Determine the Prevalence and Predictors of Disengagement and Exhaustion in Pharmacy Students

\begin{tabular}{|c|c|}
\hline & $\begin{array}{c}\text { All students, } \\
\text { No. }(\%)\end{array}$ \\
\hline \multicolumn{2}{|l|}{ Year in school } \\
\hline P1 & $71(24.9)$ \\
\hline $\mathrm{P} 2$ & $86(30.2)$ \\
\hline P3 & $128(44.9)$ \\
\hline \multicolumn{2}{|c|}{ Undergraduate path prior to pharmacy school } \\
\hline Prerequisites in 2 years & $39(13.7)$ \\
\hline Prerequisites in 3 years & $106(37.2)$ \\
\hline 4-year degree & $128(44.9)$ \\
\hline Advanced degree & $6(2.1)$ \\
\hline Other & $6(2.1)$ \\
\hline \multicolumn{2}{|l|}{ Age, y } \\
\hline $18-21$ & $16(5.6)$ \\
\hline $22-25$ & $241(84.6)$ \\
\hline 26 and older & $28(9.8)$ \\
\hline \multicolumn{2}{|l|}{ Ethnicity } \\
\hline Hispanic or Latino & $2(0.7)$ \\
\hline African American & $8(2.8)$ \\
\hline Caucasian & $245(86.3)$ \\
\hline Asian or Pacific Islander & $14(4.9)$ \\
\hline I prefer not to answer & $9(3.2)$ \\
\hline Other & $6(2.1)$ \\
\hline \multicolumn{2}{|l|}{ Career plans after graduation } \\
\hline Residency: community based & $27(9.5)$ \\
\hline Residency: hospital based & $144(50.5)$ \\
\hline Fellowship & $10(3.5)$ \\
\hline Immediately join the workforce & $87(30.5)$ \\
\hline Additional education & $4(1.4)$ \\
\hline Other & $13(4.6)$ \\
\hline \multicolumn{2}{|c|}{ Currently working during the school year } \\
\hline Yes & $216(75.8)$ \\
\hline No & $69(24.2)$ \\
\hline \multicolumn{2}{|l|}{ Work hours per week } \\
\hline N/A, not working & $69(24.2)$ \\
\hline $1-5$ & $32(11.2)$ \\
\hline $6-10$ & $95(33.3)$ \\
\hline $11-15$ & $66(23.2)$ \\
\hline $16-20$ & $17(6.0)$ \\
\hline$>20$ & $6(2.1)$ \\
\hline \multicolumn{2}{|l|}{ Co-curricular participation } \\
\hline Yes & $231(81.1)$ \\
\hline No & $54(18.9)$ \\
\hline \multicolumn{2}{|l|}{ Extra-curricular participation } \\
\hline Yes & $127(44.6)$ \\
\hline No & $158(55.4)$ \\
\hline \multicolumn{2}{|c|}{ Number of co- and extra-curricular activities } \\
\hline 0 & $23(8.1)$ \\
\hline 1 & $34(12.0)$ \\
\hline 2 & $83(29.2)$ \\
\hline
\end{tabular}

Table 1. (Continued)

\begin{tabular}{lr}
\hline & $\begin{array}{c}\text { All students, } \\
\text { No. }(\%)\end{array}$ \\
\hline 3 & $85(29.9)$ \\
4 & $40(14.1)$ \\
5 & $7(2.5)$ \\
$>5$ & $12(4.2)$ \\
Academic leadership positions & \\
$\quad$ Yes & $149(52.3)$ \\
No & $136(47.7)$ \\
Pursuing dual degree & \\
Yes & $70(24.6)$ \\
No & $215(75.4)$ \\
Married & \\
Yes & $35(12.3)$ \\
No & $250(87.7)$ \\
Children & \\
Yes & $8(2.8)$ \\
No & $277(97.2)$ \\
\hline
\end{tabular}

Students had the option to skip questions, therefore not all totals will sum to $n=291$

PY1 = first professional year, PY2=second professional year, PY3 $=$ third professional year

study on average scored consistently higher for both disengagement and exhaustion than reports from other studies using the OLBI. The mean scores for disengagement (2.7) and exhaustion (2.9) were higher than the mean disengagement and exhaustion scores for Greek (2.0 and 2.8) and German (1.9 and 2.6) college students as reported by Reis and colleagues. ${ }^{7}$ Likewise the mean disengagement and exhaustion scores from our study were higher than those of another comparison group, medical residents ( 2.4 and 2.5 , respectively), in the study by Goldhagen and colleagues. ${ }^{15}$ There are no obvious explanations as to why the rates of burnout among pharmacy students in our study were higher, but it suggests that there may be either external contributing factors and/or issues pertaining to measurement. These are briefly discussed later in this paper.

We hypothesized that students with competitive postgraduate goals would have higher burnout scores because of their self-perceived stress of completing additional extracurricular and cocurricular activities to differentiate themselves as a potential resident, fellow, or job candidate. Based on the results of this study, it was surprising to find that there were no significant differences in burnout scores based on the students' postgraduate goals. One possible explanation is that students who pursue additional education may be more engaged because of their commitment and dedication to a specific career path, and thus more protected from burnout. The results are 


\section{American Journal of Pharmaceutical Education 2020; 84 (10) Article 7945.}

Table 2. Doctor of Pharmacy Students' Responses to Items on the Oldenburg Burnout Inventory

\begin{tabular}{|c|c|c|c|c|}
\hline Survey Items $s^{\mathbf{a}, \mathbf{b}}$ & $\begin{array}{l}\text { Strongly Agree, } \\
\text { No. }(\%)\end{array}$ & $\begin{array}{l}\text { Agree, } \\
\text { No. }(\%)\end{array}$ & $\begin{array}{c}\text { Disagree, } \\
\text { No. }(\%)\end{array}$ & $\begin{array}{c}\text { Strongly Disagree } \\
\text { No. }(\%)\end{array}$ \\
\hline $\begin{array}{l}\text { 1. I always find new and interesting aspects in } \\
\text { my curriculum. }\end{array}$ & $37(12.7)$ & $192(66.0)$ & $56(19.2)$ & $6(2.1)$ \\
\hline $\begin{array}{l}\text { 2. There are days I feel tired before I arrive to } \\
\text { school. }^{c}\end{array}$ & $224(77.0)$ & $65(22.3)$ & $1(0.3)$ & $1(0.3)$ \\
\hline $\begin{array}{l}\text { 3. It happens more and more often that I talk } \\
\text { about my school in a negative way. }\end{array}$ & $99(34.0)$ & $132(45.4)$ & $55(18.9)$ & $5(1.7)$ \\
\hline $\begin{array}{l}\text { 4. After school, I tend to need more time than in } \\
\text { the past in order to relax and feel better. }\end{array}$ & $120(41.2)$ & $132(45.4)$ & $36(12.4)$ & $3(1.0)$ \\
\hline 5. I can tolerate the pressure of school very well. & $27(9.3)$ & $186(63.9)$ & $71(24.4)$ & $7(2.4)$ \\
\hline $\begin{array}{l}\text { 6. Lately, I tend to think less at school and do } \\
\text { the work almost mechanically. }\end{array}$ & $42(14.7)$ & $162(56.6)$ & $77(26.9)$ & $5(1.7)$ \\
\hline 7. I find school to be a positive challenge. & $16(5.6)$ & $191(67.0)$ & $71(24.9)$ & $7(2.5)$ \\
\hline 8. During school I feel emotionally drained. ${ }^{c}$ & $113(39.5)$ & $122(42.7)$ & $46(16.1)$ & $5(1.7)$ \\
\hline $\begin{array}{l}\text { 9. Over time, one can become disconnected } \\
\text { from the classroom. }{ }^{\text {c }}\end{array}$ & $125(43.7)$ & $146(51.0)$ & $12(4.2)$ & $3(1.0)$ \\
\hline $\begin{array}{l}\text { 10. After school, I have enough energy for my } \\
\text { leisure activities. }\end{array}$ & $13(4.5)$ & $94(32.9)$ & $146(51.0)$ & $33(11.5)$ \\
\hline 11. Sometimes I feel sickened by my school tasks. ${ }^{\mathrm{c}}$ & $79(27.7)$ & $127(44.6)$ & $74(26.0)$ & $5(1.8)$ \\
\hline $\begin{array}{l}\text { 12. After school, I usually feel worn out and } \\
\text { weary. }\end{array}$ & $81(28.4)$ & $159(55.8)$ & $44(15.4)$ & $1(0.4)$ \\
\hline $\begin{array}{l}\text { 13. Pharmacy is the only type of career I can } \\
\text { imagine myself doing. }\end{array}$ & $62(21.8)$ & $63(22.2)$ & $128(45.1)$ & $31(10.9)$ \\
\hline $\begin{array}{l}\text { 14. Usually, I can manage my amount of } \\
\text { schoolwork well. }\end{array}$ & $32(11.2)$ & $211(74.0)$ & $32(11.2)$ & $10(3.5)$ \\
\hline 15. I feel more and more engaged in school. & $7(2.5)$ & $64(22.5)$ & $181(63.5)$ & $33(11.6)$ \\
\hline $\begin{array}{l}\text { 16. When I am at school, I usually feel } \\
\text { energized. }\end{array}$ & $2(0.7)$ & $43(15.1)$ & $187(65.8)$ & $52(18.3)$ \\
\hline
\end{tabular}

a Students had the option to skip questions, therefore not all totals will sum to 291

${ }^{\mathrm{b}}$ Questions associated with engagement include 2, 4, 5, 8, 10, 12, 14, 16 and questions associated with disengagement include 1, 3, 6, 7, 9, 11, 13, 15

${ }^{\mathrm{c}}$ Indicates a reverse scored item, in which lower scores indicate more burnout

similar to those reported by Jones who explored the relationship between employee engagement, job satisfaction, and organizational commitment and found a significant relationship between commitment and engagement. ${ }^{16}$

We also hypothesized that students who were more involved in co-curricular and extracurricular activities would have higher rates of burnout because of overcommitment. We assessed aspects such as work hours in a week, extracurricular and cocurricular activities, as well as leadership commitments in our study and found these had no impact on burnout scores. These results conflict with those of a similar study by Avanzi and colleagues who found a correlation between overcommitted employees and higher rates of burnout over time. ${ }^{17}$ Higher workload has also been associated with burnout risk among clinical pharmacists, physicians, and nurses. ${ }^{18,19}$ We hypothesized that heavy involvement with school and professional activities serves as a protective factor and prevents higher degrees of burnout because of their genuine interest in what they are learning. This hypothesis is supported by the works of Moodie and colleagues and Fragosa and colleagues whose research details the important but complex connections between engagement and overall burnout. ${ }^{20,21}$

Higher burnout scores of $\mathrm{P} 1$ students as compared to P2 and P3 students in this study could potentially be explained by the nature of the PharmD curriculum. Firstyear students have challenging coursework and the adjustments required to transition from an undergraduate student to a professional student may eventually take a toll. However, our P1 students scoring highest for burnout differed from findings of Silva and Figueiredo-Braga. ${ }^{11}$ Their results showed that students further along in their pharmacy career are more likely to show signs of burnout as a result of depersonalization. They also found that higher burnout scores negatively correlated with academic satisfaction, and that this dissatisfaction could potentially contribute to disengagement in the classroom. ${ }^{11}$ 
American Journal of Pharmaceutical Education 2020; 84 (10) Article 7945.

Table 3. T-test Results for Variables Included in Regression Modeling for Students at High Risk of Burnout

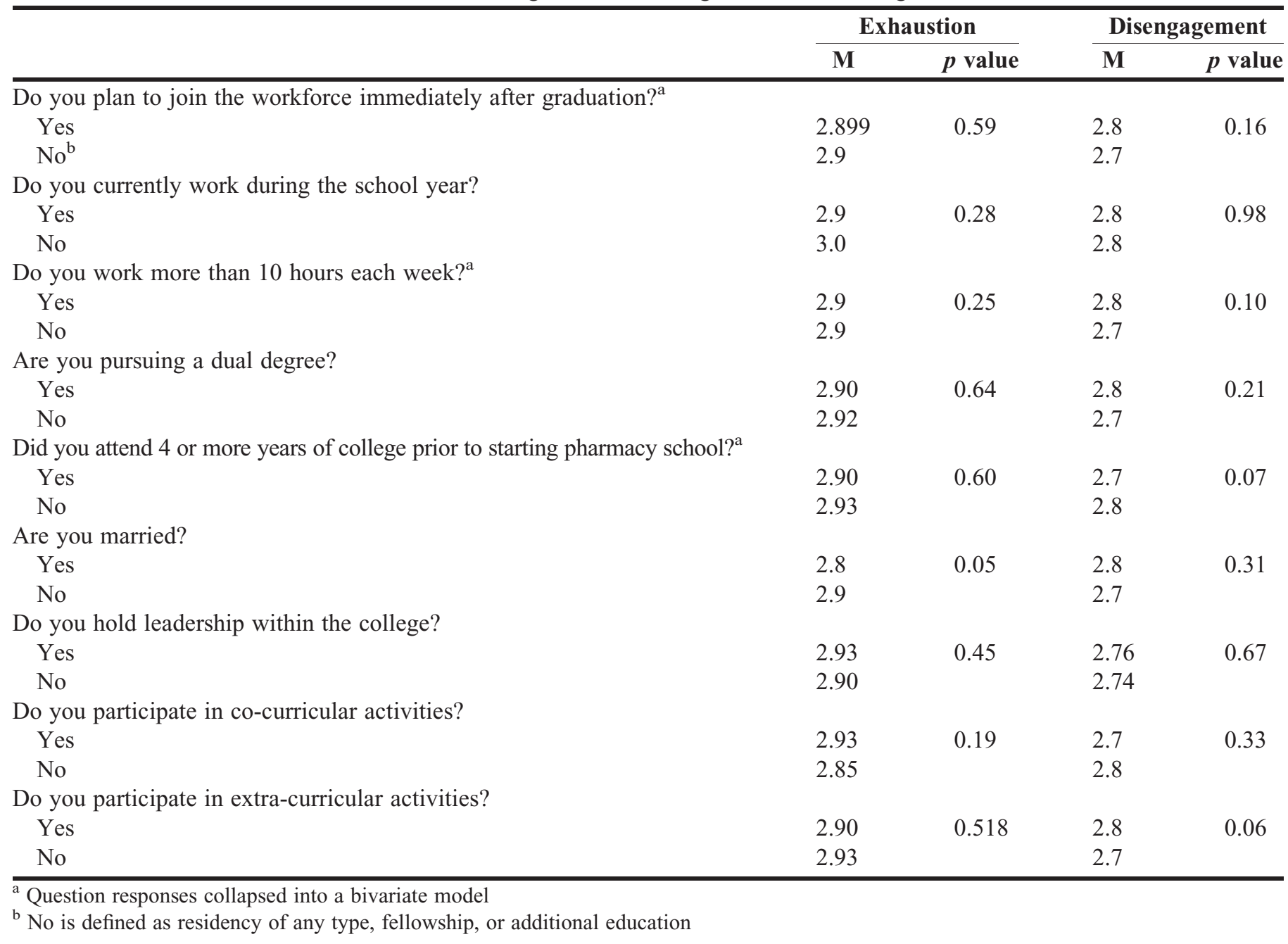

Importantly, Silva and Figueiredo-Braga's results should also be interpreted against their own curriculum, which differs from typical US programs.

Surprisingly, the only factor that was predictive for student burnout scores in our study was marriage. Results showed that students who were married at the time they completed the survey had statistically lower exhaustion scores. There are several potential reasons for this finding. It could be that students who are in different stages of life (eg, married vs single) experience different pressures in life and/or perceive them differently. Students who are married may also have a better support system then students who are not. Our results compare favorably with those from other studies of health care professionals that examined marriage and burnout. Saleh and colleagues assessed key factors that contribute to burnout in orthopedic surgery leaders and how a strong family and spousal support system can prevent this. They concluded that a spouse who is an active listener and consciously makes efforts to strengthen the marital bond can aid a student in managing his or her stress. ${ }^{22}$ In another study, Ifeagwazi found that nurses who were married had lower burnout scores than those who were widowed. ${ }^{23}$ Finally, Moss and colleagues and Ohue and colleagues found that health care practitioners who were married report lower levels of burnout. $^{24,25}$ These studies suggest that spousal support may be an important protective factor for burnout.

There are several limitations to this study that should be noted when interpreting the results. First, this study was conducted at a single institution. By assessing multiple colleges of pharmacy, including various program types across various states, a more comprehensive assessment of the prevalence of pharmacy student burnout could be conducted. Second, gender could potentially be a confounding variable and that information was not collected nor assessed in our study. Third, when interpreting the results, the timing of this survey should also be considered, as it was distributed three weeks prior to final examinations. Higher stress levels during a demanding time period could have contributed to higher than average 


\section{American Journal of Pharmaceutical Education 2020; 84 (10) Article 7945.}

burnout scores. Finally, the modifications we made to the OLBI questions had not been formally validated.

Further research is needed to delineate between high stress and burnout in pharmacy students. Stress may affect how pharmacy students think about and respond to burnout inventory questions. Also, because students' stress levels may differ within and across semesters, timepoint comparisons should be made throughout the school year to determine if burnout is higher or lower at different points and if stress levels improperly inflate burnout scores. This study also only assessed personal factors that may contribute to burnout. Institutional, curricular, and even professional demands may play an equal or greater role in student burnout than personal factors. Those external factors need to be researched as well.

\section{CONCLUSION}

While this pilot study revealed that PharmD students may have relatively high rates of burnout, it is still unclear what contributes to some students scoring significantly higher than others. Aside from year in school and marriage, no significant differences were found in the other variables explored. Further analysis of positive and negative predictive factors associated with burnout scores would allow the development of targeted resources for students most susceptible to burnout early in their academic career. By examining additional personal and school characteristics, assessing the role of gender, and potentially using other assessment tools, a more comprehensive understanding of contributors to burnout could be made.

\section{REFERENCES}

1. National Academy of Medicine. National collaborative on clinician well-being and resilience. https://nam.edu/initiatives/ clinician-resilience-and-well-being/commitment-statementsclinician-well-being/. Published 2019. Accessed September 16, 2020. 2. American Society of Health-System Pharmacists. Workforce well-being and resilience: ASHP. https://wellbeing.ashp.org/. Published 2019. Accessed September 16, 2020.

3. American Association of Colleges of Pharmacy. Wellness and Resilience in Pharmacy Education. https://www.aacp.org/resource/ wellness-and-resilience-pharmacy-education. Published 2019.

Accessed September 16, 2020.

4. Merriam-Webster. Burnout. https://www.merriam-webster.com/ dictionary/burnout. Published 2019. Accessed September 16, 2020.

5. World Health Organization. Burn-out an "occupational phenomenon": International classification of diseases. https://

www.who.int/mental_health/evidence/burn-out/en/. Published 2019. Accessed September 16, 2020.

6. Maslach C, Schaufeli WB, Leiter MP. Job burnout. Annu Rev Psychol. 2001;52(1):397-422.

7. Reis D, Xanthopoulou D, Tsaousis I. Measuring job and academic burnout with the Oldenburg Burnout Inventory (OLBI): Factorial invariance across samples and countries. Burnout Res. 2015;2(1):8-18.
8. Rothenberger DA. Physician burnout and well-being: a systematic review and framework for action. Dis Colon Rectum. 2017;60(6): 567-576.

9. Frajerman A, Morvan Y, Krebs M-O, Gorwood P, Chaumette B. Burnout in medical students before residency: A systematic review and meta-analysis. Eur Psychiatry. 2019;55:36-42.

10. Rachiotis G, Kourousis C, Kamilaraki M, Symvoulakis EK, Dounias G, Hadjichristodoulou C. Medical supplies shortages and burnout among Greek health care workers during economic crisis: a pilot study. Int J Med Sci. 2014;11(5):442-447.

11. Silva RG, Figueiredo-Braga M. The roles of empathy, attachment style, and burnout in pharmacy students' academic satisfaction. Am J Pharm Educ. 2019;83(5):Article 6706.

12. Kaur M, Long JW, Sang Luk F, et al. Burnout and engagement in doctor of pharmacy students: its relation to perception of academic ability. Am J Pharm Educ. 2020;84(2):Article 7571.

13. Demerouti E, Mostert K, Bakker AB. Burnout and work engagement: a thorough investigation of the independency of both constructs. J Occup Health Psychol. 2010;15(3):209.

14. Sinval J, Queirós C, Pasian S, Marôco J. Transcultural adaptation of the Oldenburg Burnout Inventory (OLBI) for Brazil and Portugal. Front Psychol. 2019;10:Article 338.

15. Goldhagen BE, Kingsolver K, Stinnett SS, Rosdahl JA. Stress and burnout in residents: impact of mindfulness-based resilience training. Adv Med Educ Pract. 2015;6:525.

16. Jones R. The relationship of employee engagement and employee job satisfaction to organizational commitment [dissertation].

Minneapolis, Walden University; 2018.

17. Avanzi L, Zaniboni S, Balducci C, Fraccaroli F. The relation between overcommitment and burnout: does it depend on employee job satisfaction? Anxiety Stress Coping. 2014;27(4): 455-465.

18. Haase KK. Addressing burnout in clinical pharmacy: what can we learn from other health care disciplines? J Am Coll Clin Pharm. 2019.

19. Jones GM, Roe NA, Louden L, Tubbs CR. Factors associated with burnout among US hospital clinical pharmacy practitioners: results of a nationwide pilot survey. Hosp Pharm.

2017;52(11):742-751.

20. Fragoso ZL, Holcombe KJ, McCluney CL, Fisher GG, McGonagle AK, Friebe SJ. Burnout and engagement: Relative importance of predictors and outcomes in two health care worker samples. Workplace Health Saf. 2016;64(10):479-487.

21. Moodie S, Dolan SL, Burke RJ. Engagement vs. Burnout: An Examination of the RelationshipsBbetween the Two Concepts Within the Framework of the JDR Model. Barcelona: Ramon Llull

University;2012.

22. Saleh KJ, Quick JC, Sime WE, Novicoff WM, Einhorn TA. Recognizing and preventing burnout among orthopaedic leaders. Clin Orthop Relat Res. 2009;467(2):558-565.

23. Ifeagwazi FCM. The influence of marital status on self-report of symptoms of psychological burnout among nurses. OMEGA-J Death Dying. 2006;52(4):359-373.

24. Moss M, Good VS, Gozal D, Kleinpell R, Sessler CN. A Critical Care Societies collaborative statement: Burnout syndrome in critical care health-care professionals. A call for action. Am J Respir Crit Care Med. 2016;194(1):106-113.

25. Ohue T, Moriyama M, Nakaya T. Examination of a cognitive model of stress, burnout, and intention to resign for Japanese nurses. Jpn J Nurs Sci. 2011;8(1):76-86. 